\title{
Discovery of a Pederin Family Compound in a Nonsymbiotic Bloom-Forming Cyanobacterium
}

\section{Kust, Andreja}

2018-05

Kust , A, Mares , J , Jokela , J , Urajova , P , Hajek, J , Saurav , K, Voracova , K, Fewer , D P , Haapaniemi , E , Permi , P , Rehakova , K , Sivonen , K \& Hrouzek , P 2018 , ' Discovery of a Pederin Family Compound in a Nonsymbiotic Bloom-Forming Cyanobacterium ' , ACS Chemical Biology, vol. 13 , no. 5 , pp. 1123-1129 . https://doi.org/10.1021/acschembio.7b0

http://hdl.handle.net/10138/327284

https://doi.org/10.1021/acschembio.7b01048

acceptedVersion

Downloaded from Helda, University of Helsinki institutional repository.

This is an electronic reprint of the original article.

This reprint may differ from the original in pagination and typographic detail.

Please cite the original version. 


\title{
Discovery of a Pederin Family Compound in a Nonsymbiotic Bloom-Forming Cyanobacterium
}

Andreja Kust ${ }^{1,2,3^{*}}$, Jan Mareš ${ }^{1,2,3^{*}}$, Jouni Jokela ${ }^{4}$, Petra Urajová ${ }^{1}$, Jan Hájek ${ }^{1,3}$, Kumar Saurav ${ }^{1}$, Kateřina Voráčová ${ }^{1}$, David P. Fewer ${ }^{4}$, Esa Haapaniemi ${ }^{5}$, Perttu Permi ${ }^{5,6}$, Kaarina Sivonen ${ }^{4}$ and Pavel Hrouzek ${ }^{1,3}$ ${ }^{1}$ Institute of Microbiology CAS, Center Algatech, Třeboň, Czech Republic;

${ }^{2}$ The Czech Academy of Sciences, Biology Centre, Institute of Hydrobiology, České Budějovice, Czech Republic;

${ }^{3}$ University of South Bohemia, Faculty of Science, České Budějovice, Czech Republic; ${ }^{4}$ Department of Food and Environmental Sciences, University of

Helsinki, Helsinki, Finland;

${ }^{5}$ Department of Chemistry, University of Jyvaskyla, Fl-40010 Jyvaskyla, Finland

${ }^{6}$ Department of Biology and Environmental Science, Nanoscience Center, University of Jyvaskyla, FI40010 Jyvaskyla, Finland

*These authors contributed equally to this work

Correspondence: P Hrouzek, Institute of Microbiology CAS, Center Algatech, Novohradská 237, Opatovický Mlýn, 37981 Třeboň, Czech Republic, Email: hrouzekp@gmail.com, Tel.: +420-384-340470, Fax: +420-384-340-415.

\begin{abstract}
The pederin family includes a number of bioactive compounds isolated from symbiotic organisms of diverse evolutionary origin. Pederin is linked to beetle-induced dermatitis in humans, and pederin family members possess potent antitumor activity caused by selective inhibition of the eukaryotic ribosome. Their biosynthesis is accomplished by a polyketide/nonribosomal peptide synthetase machinery employing an unusual trans-acyltransferase mechanism. Here, we report a novel pederin type compound, cusperin, from the free-living cyanobacterium Cuspidothrix issatschenkoi (earlier Aphanizomenon). The chemical structure of cusperin is similar to that of nosperin recently isolated from the lichen cyanobiont Nostoc sharing the tehrahydropyran moiety and major part of the linear backbone. However, the cusperin molecule is extended by a glycine residue and lacks one hydroxyl substituent. Pederins were previously thought to be exclusive to symbiotic relationships. However, $\mathrm{C}$. issatschenkoi is a nonsymbiotic planktonic organism and a frequent component of toxic water blooms. Cusperin is devoid of the cytotoxic activity reported for other pederin family members. Hence, our findings raise questions about the role of pederin analogues in cyanobacteria and broaden the knowledge of ecological distribution of this group of polyketides.
\end{abstract}


Pederin is a toxin containing two tetrahydropyran cores that causes dermatitis.1 Pederin was first reported from the

beetle Paederus $f$ uscipes and widely believed to be produced by eukaryotes.2,3 However, the discovery of the pederin biosynthetic gene cluster demonstrated that bacterial symbionts of insects, marine invertebrates, and lichens are the true producers of these compounds. 4 Biosynthesis of pederin and its homologues is accomplished by hybrid polyketide/nonribosomal peptide synthases (PKS/NRPS) employing an unusual trans-acyltransferase (AT) PKS mechanism, 5 in which the PKS enzymatic modules utilize a common AT encoded in a separate gene. The biosynthesis of all pederin family compounds seems to share the first several steps forming the typical tetrahydropyran moiety attached to an acyl chain with a glycine residue. 6 Metagenomic sequencing of symbiotic consortia has recently uncovered a large and highly specific repertoire of natural products, particularly in bacterial symbionts of marine sponges.7,8 Pederins are currently also believed to be specifically associated with prokaryote-eukaryote symbioses as they have been reported exclusively from symbiotic associations.6,7,9-11 However, a recent discovery of a pederin analogue in a purportedly free-living strains of cyanobacterium Nostoc sp. KVJ1012 and proteobacterium Labrenzia sp. PHM00513 isolated from the soil arond the Nostoc hosting moss Blasia and marine sediment, respectively, challenged this hypothesis. The potential of free-living organisms to produce pederins is further corroborated with our report of a novel pederin analogue, cusperin, identified for the first time in a nonsymbiotic cyanobacterium, Cuspidothrix issatschenkoi (Usačev) Rajaniemi et al. Cuspidothrix (earlier Aphanizomenon) is a frequent bloomforming species in freshwater bodies, 14 which belongs to the lineage of typical freshwater planktonic heterocytous cyanobacteria, clearly distant from all groups of the typical pederin producers (Figure 1). Inspection of a draft genome of C. issatschenkoi strain CHARLIE-1 led to the identification of a previously unreported PKS/NRPS gene cluster, exhibiting $>70 \%$ similarity with the nosperin biosynthetic gene cluster. 6 The core region of this biosynthetic gene cluster is almost identical to that reported for pederin compounds (Figure 2a, Supporting Information Tables 1 and 2). The putative biosynthetic gene cluster $(\sim 54 \mathrm{~kb})$ consisted of 11 protein coding ORFs: two genes encoding multidomain PKS/NRPS proteins, eight accessory genes, and a single gene encoding a peculiar AT in the trans position (Figure 2a). Further evidence suggesting the presence of a transAT PKS system in the cusperin synthetase is the absence of AT domains in the deduced PKS proteins (Figure $2 b$ ). Detailed analysis of the individual components of the gene cluster are provided in the Supporting Information. Analysis of methanol extracts of C. issatschenkoi CHARLIE1 led to the identification of two putative products of the PKS/ NRPS gene cluster. Their chemical structures were elucidated using a combination of high-performance liquid chromatography connected to high resolution mass spectrometer with electrospray ionization (HPLC-ESIHRMS/MS) and nuclear magnetic resonance (NMR) spectroscopy (Figures 3 and 4 Supporting Information Figures 1-6, Supporting Information Tables 3 and 4). A prominent chromatographic peak was obtained by HPLC-MS analysis of Cuspidothrix extract containing a compound detected at $\mathrm{m} / \mathrm{z}=561.2896[\mathrm{M}+\mathrm{Na}]+$ with a calculated elemental composition of $\mathrm{C} 26 \mathrm{H} 42 \mathrm{~N} 4 \mathrm{O} 8+\mathrm{Na}+(\Delta 0.2$ $\mathrm{ppm}$ ) corresponding to cusperin A (Figure 3). Its MS/MS exhibited attributes analogous to those reported for nosperin, e.g., the loss of methanol (producing ion a) and the loss of a whole substituted tetrahydropyran moiety (producing ion b) identical to those of nosperin6 (Figure 3b). Data from the analysis of $1 \mathrm{H}, 1 \mathrm{H}-1 \mathrm{H}$ NOESY, 13C HSQC, 13C HMBC, and 15N HSQC spectra (Supporting Information Figures 1-5) of cusperin showed high similarity to nosperin NMR data,6 which proved that their general structure was the same (Supporting Information Table 4). 
Compared to nosperin, cusperin lacked C-28 hydroxyl. C-20 hydroxyl was changed to carbonyl, and next to it there was an extra amide group (C-21-NH). Due to the lack of the hydroxyl, C-28 showed a methyl signal $(\delta C 19.8, \delta H 1.00)$, and this difference affected the nearby shift values (Supporting Information Table 4). Four carbonyl signals were found (Supporting Information Figure 3), one more than in nosperin as one hydroxyl of nosperin is replaced with carbonyl in cusperin. The cusperin NH-9 signal ( $d, \delta H ~ 8.40$ ) matched with nosperin ( $d, \delta H ~ 8.57)$. The extra C-21-NH signal $(\mathrm{dd}, \delta \mathrm{H} 7.11$ ) of cusperin was broad, but the signals' dd structure could be seen, which was characteristic for glycine in peptide structures. $15 \mathrm{~N}-H S Q C$ spectrum showed the $\delta \mathrm{H} 7.11$ proton connection to a nitrogen atom (Supporting Information Figure 4). The most important 13C-HMBC and $1 \mathrm{H}-1 \mathrm{H}$ NOESY correlations are shown in Supporting Information Figure 4. The MS/MS analysis further detected the presence of a second cusperin variant with $\mathrm{m} / \mathrm{z}$ at $547.2740[\mathrm{M}+\mathrm{Na}]+$ and calculated elemental composition of $\mathrm{C} 25 \mathrm{H} 40 \mathrm{~N} 4 \mathrm{O} 8+\mathrm{Na}+(\Delta-0.3 \mathrm{ppm})$. While cusperin A provided ions corresponding to $[\mathrm{MCH} 2 \mathrm{OH}+\mathrm{H}]+$ in both $\mathrm{MS}$ and $\mathrm{MS} / \mathrm{MS}(\mathrm{m} / \mathrm{z} 507.2812, \Delta 0.3 \mathrm{ppm})$, cusperin B provided only a $[\mathrm{M}-\mathrm{H} 2 \mathrm{O}+\mathrm{H}]+$ fragment (Supporting Information Figure 6). This corresponds to the losses of a methoxy and a hydroxy group from the molecular ion of cusperin $A$ and $B$, respectively. On the basis of the combination of MS and NMR data, we concluded that cusperin A presents the methylacetal variant (bearing methoxy group on C-6), and cusperin B presents the hemiacetal variant (bearing hydroxy group on C-6). Purification (see Supporting Information Table 5) yielded $0.3 \mathrm{mg}$ of cusperin A and B in a molar ratio of 70:30 (Supporting Information Figure 6). The origin of the structural differences between cusperin and nosperin as well as the occurrence of cusperin $A$ and $B$ variants were explained by bioinformatic prediction of cusperin biosynthesis (Figure $2 \mathrm{~b}$ ). First, the presence of a terminal glycine in cusperin instead of a reduced biketide was consistent with an additional NRPS module encoded in cusC containing an A domain with a predicted substrate specificity for glycine (Supporting Information Table 2). The second difference observed was the lack of the hydroxyl on C-12 in cusperin, explained by the lack of cytochrome-450 like protein responsible for the hydroxylation step in nosperin. 6 Four nitrogen atoms were predicted in the cusperin scaffold based on the presence of three NRPS modules each incorporating a single amino acid and an asparagine synthetase responsible for the final transamination step (Figure $2 \mathrm{~b}$ ). The number of nitrogen atoms was further confirmed by $15 \mathrm{~N}$ isotopic substitution ( $\mathrm{m} / \mathrm{z}$ at $565.2685, \Delta-0.9 \mathrm{ppm})$. The predicted product of cusF was an Omethyltransferase, likely involved in facultative O-methylation of the hydroxy group at $\mathrm{C6}$, which results in formation of the observed cusperin methylacetal/ hemiacetal variants (cusperin $A$ and B). The individual predicted biosynthetic steps are explained in detail in Supporting Information. The cusperin gene cluster exhibited high similarity in the arrangement of the first five PKS/NRPS modules to those observed in several pederin members (pederin, theopederins, mycalamides, onnamides), which allowed us to infer the absolute configuration at chiral carbons $\mathrm{C} 2, \mathrm{C} 3, \mathrm{C6}$, and C7

(Figure $4 \mathrm{~b}$ ). In addition, the arrangement of the first 10 modules was consistent with the nosperin gene cluster, further

suggesting the configuration of $\mathrm{C} 10, \mathrm{C} 11$, and $\mathrm{C} 13$ are identical to nosperin. Comparison of the NMR coupling constants and shift values (Supporting Information Table 4) further indicates that the stereochemistry is likely identical between these two compounds (Figure $4 \mathrm{~b}$ ). Bioinformatics analysis of the specific sequence motifs of the KR domains has again confirmed D-OH configuration at $\mathrm{C} 2$ and $\mathrm{C} 13$ based on the presence of a conserved aspartate residue recently demonstrated to play a key role in stereospecificity of the KR domain15-17 (Supporting Information Table 6). Finally, the lack of the epimerization domain in the NRPS module 10 
supported the incorporation of an L-Pro residue as per bioinformatics analysis of pathway A domains. Equivalent to nosperin, $\mathrm{C} 12$ and $\mathrm{C} 14$ remained without stereochemical assignments. The strong cytotoxic activity of pederin family members was found due to their specific binding to the large ribosomal subunit.18 Recent structure-activity studies defined the key features of pederin analogues involved in their action.19 First, the presence of alkoxy or hydroxy substitution at C10 facilitates the molecule rotation and subsequent binding, while the lack of any substituent at this position leads to diminished activity.19 Additionally, the presence of a methoxy group at C13 is favored over the hydroxyl group. In comparison to other natural pederin analogues, cusperin $A$ and B exhibited only weak cytotoxic activity (Supporting Information Table 7). The cusperin molecule features both traits, which do not favor the interaction with ribosome as $\mathrm{C} 10$ is not functionalized and $\mathrm{C} 13$

bears the less efficient $-\mathrm{OH}$ group. The bioactivity of cusperin demonstrates that not all natural pederin analogues exert high cytotoxic activity, and thus they do not act generally and exclusively as ribosome poisons. Interestingly, high production levels of cusperin A and B were recorded in the Cuspidothrix culture (up to $2.5 \mathrm{mg} / \mathrm{g}$ of dry weight). With regard to the high content and easy isolation protocol, discovery of cusperin opens up an opportunity to address the ecological role of this type of compound. Cuspidothrix, a bloom-forming cyanobacterium which has the potential to produce compounds that are a threat to human health, 20 has been characterized as the first freeliving cyanobacterium producing a pederin-type compound, cusperin. Our findings contradict the recently suggested restricted occurrence of pederin family members in symbiotic bacteria and dispute their general role directly associated with specific symbioses between eukaryotes and bacteria. 6 Cusperin production may however play a role in other microbe-microbe relationships occurring in freshwater blooms that are currently not well characterized. The selective advantage for the production of a pederin family compound by a nonsymbiotic organism remains unknown, and further studies are needed to decipher its possible ecological significance, especially as cytotoxic activity is weak compared to other pederins.

\section{METHODS}

Cultivation of the Strain. C. issatschenkoi CHARLIE-1 was isolated from a water bloom sample collected from fishpond Papez near Dobř́šs, Czech Republic. A monoclonal culture was established from a single filament and maintained in the culture collection of the Biology Centre of CAS, Institute of Hydrobiology in $250 \mathrm{~mL}$ Erlenmeyer flasks with WC medium 21 at $21^{\circ} \mathrm{C}$ and a light intensity of $50 \mu \mathrm{mol} \mathrm{m}-2 \mathrm{~s}-1$ (16:8 L/D cycle). For the isolation procedure, the batch culture of the strain was grown in $10 \mathrm{~L}$ Erlenmeyer flasks using BG-11 medium bubbled with $1.5 \%$ CO2 enriched

air at $25^{\circ} \mathrm{C}$ with an illumination of $100 \mu \mathrm{mol} \mathrm{m}-2 \mathrm{~s}-1$. The biomass for isolation of $15 \mathrm{~N}$ isotopically substituted cusperin was cultivated under the same cultivation conditions in BG-11 medium supplemented with Na15NO3 (Sigma-Aldrich, Cat. No. 364606), and the culture was reinoculated twice, each time after 20 days of cultivation period. Strain identification was performed based on morphological characters 22 and position in a phylogenetic tree based on the $16 \mathrm{~S}$ rRNA gene.

Phylogenetic Analysis. The $16 \mathrm{~S}$ rRNA gene sequences of pederin family compound producers available through NCBI and the cusperin producer C. issatschenkoi CHARLIE-1 were aligned with a set of closest BLAST hits, representatives of the corresponding bacterial phyla, and a representative set of cyanobacterial sequences. A phylogenetic tree was constructed using the Bayesian inference. See the Supporting Information for details. 
Genomic and Bioinformatic Analysis. Single filaments of C. issatschenkoi CHARLIE-1 were isolated using the glass capillary technique and prepared for whole genome sequencing as described previously.23 The filaments were utilized as a template for wholegenome amplification by multiple-displacement amplification (MDA) using a Repli-G Mini Kit (Qiagen). Sixteen MDA products that passed the quality check were pooled and sent for commercial de novo genome sequencing (EMBL Genomics Core Facility, Heidelberg, Germany) using an Illumina MiSeq Pair-End library with 250 bp reads, $350 \mathrm{bp}$ average insert length, and $1.4 \mathrm{Gbp}$ data yield. The data from Illumina were assembled using CLC Bio Genomics Workbench v. 10.5 (Qiagen). The genomic assembly is available under NCBI accession number PGEM00000000.1, and the cusperin biosynthetic gene cluster is available under accession number MG518226. Genomic scaffolds were investigated using BLASTp in the Geneious Pro R10 (Biomatters) software package to identify putative PKS/NRPS gene clusters, employing cyanobacterial A domains and KS domains as queries. In target genomic regions, open reading frames were predicted (Glimmer 3).24 The deduced proteins were functionally annotated (BLASTp and CDD searches), and in the putative PKS/NRPS proteins individual enzymatic domains were identified (antiSMASH 4.0).25 The substrate specificities of KS domains in the trans-AT PKS modules were predicted based on similarity to the closest functionally characterized hits in the BLASTp analysis (Supporting Information Table 2), which were unequivocally represented by KS domains from the nosperin pathway (analyzed by phylogenetics in a previous study6). The predicted specificity of NRPS adenylation domains was inferred using a combination of tools implemented in antiSMASH 4.0 (Stachelhaus code, NRPS Predictor3, pHMM search). A biosynthetic scheme was constructed based on the functional annotation of the deduced PKS/NRPS domains and accessory enzymes, and by comparing to known biosynthesis pathways of pederin-family compounds. Stereochemical assignment of cusperin was assessed based on NMR data, specific KR sequence motifs,15-17 and overall arangement of NRPS/PKS modules.15

HPLC-ESI-HRMS. The crude extract of $\mathrm{C}$. issatschenkoi CHARLIE-1 was analyzed using a highperformance liquid chromatograph (Dionex UltiMate 3000 UHPLC+ (Thermo Scientific, Sunnyvale, CA, USA)) connected to a Bruker Impact HD high resolution mass spectrometer (Bruker, Billerica, Massachusetts, USA) with electrospray ionization in positive mode. Separation was performed on an RP-C18 column (Phenomenex Kinetex, $2.6 \mu \mathrm{m} ; 4.6 \times 150$, Torrance, CA, USA) using H2O (A) and acetonitrile (B) (both containing $0.1 \% \mathrm{HCOOH}$ ) as a mobile phase at a flow rate of $0.5 \mathrm{~mL} \mathrm{~min}-1$. The linear gradient was as follows: A/B 85/15 (0 min), 85/15 (in $1 \mathrm{~min}$ ), 0/100 (in $19 \mathrm{~min}$ ), 0/ 100 (in $25 \mathrm{~min}$ ), and 85/15 (in $30 \mathrm{~min}$ ). The following settings of the mass spectrometer were used: drying temperature, $200^{\circ} \mathrm{C}$; drying gas flow, $12 \mathrm{~L}$ min-1; nebulizer gas pressure, 3 bar; capillary voltage, $3.8 \mathrm{kV}$; end plate offset, $500 \mathrm{~V}$. Spectra were collected in the range $\mathrm{m} / \mathrm{z} 20-2000$ with a spectra rate of $2 \mathrm{~Hz}$. Automated fragmentation was used in the method with a precursor ion selection of $20-2000 \mathrm{~m} / \mathrm{z}$ for an isolation window width of $1 \mathrm{Da}$. The ramping of the collision energy was based on the molecular mass: $20 \mathrm{eV}$ at $400 \mathrm{~m} / \mathrm{z}$ and $70 \mathrm{eV}$ at $1000 \mathrm{~m} / \mathrm{z}$ for analysis. The mass spectrometer was calibrated with sodium formate clusters at the beginning of each analysis. Further, the lock mass calibration was applied during the analysis using hexakis $(1 \mathrm{H}, 1 \mathrm{H}, 2 \mathrm{H}$-perfluoroethoxy) phosphazene (ES-TOF m/z 622.02896, 97\%) purchased from ABCR GmbH \& Co., KG, Germany. Quantification of cusperin A and B in the C. issatschenkoi CHARLIE-1 extract was performed using the method described above with purified compounds as external standards (concentrations 2.5, 5, 10, 25, 50, and $100 \mu \mathrm{g} \mathrm{mL}-1$ were used to establish the calibration curve). See the Supporting Information for details. 
Extraction, Purification, and Quantification. Freeze-dried biomass of C. issatschenkoi CHARLIE-1 was extracted twice with $400 \mathrm{~mL}$ methanol/water (40/60, v/v) using bath sonicator, resulting supernatants were combined and partially evaporated on rotary evaporator and remaining solvent was diluted by distilled water so that the final $\mathrm{MeOH}$ concentration did not exceed $5 \%$. Further the sample was loaded on DCS 18 SPE cartridge and retained compounds were eluted with $\mathrm{MeOH}$. Eluent was evaporated until dryness and reconstituted in $10 \mathrm{~mL}$ of $\mathrm{MeOH}$ prior the highperformance liquid chromatography (HPLC) purification. The compounds were purified using three consecutive preparative HPLC separation steps (for detailed information on the purification procedure see the Supporting Information).

Nuclear Magnetic Resonance Spectroscopy. All NMR spectra were collected using a Bruker Avance III HD $800 \mathrm{MHz} N M R$

spectrometer, equipped with a cryogenically cooled $\mathrm{TCI} 1 \mathrm{H}, 13 \mathrm{C}, 15 \mathrm{~N}$ triple resonance probehead. Data were collected at $25^{\circ} \mathrm{C}$. For the assignment of cusperin $1 \mathrm{H}, 13 \mathrm{C}$, and $15 \mathrm{~N}$ resonances, a $1 \mathrm{H}$ preset experiment along with two-dimensional total correlation spectroscopy (TOCSY) and nuclear Overhauser effect spectroscopy (NOESY) experiments as well as heteronuclear single quantum coherence (13C HSQC and 15N HSQC) and heteronuclear multiple bond correlation (13C HMBC) experiments were employed. For details of the NMR measurement, please see the Supporting Information.

Cytotoxicity Testing. In order to test the antiproliferative and cytotoxic activity usually reported for pederin family members, cusperin bioactivity was tested on human cervical cancer cells (HeLa). For cell maintenance and plating before the experiment, see

the Supporting Information. Serial dilutions (in the range from $0.5-20 \mu \mathrm{M}$ ) of cusperin A and B variants were added as technical triplicates, so the concentration of the vehicle $(\mathrm{MeOH})$ did not exceed $1 \%$. The viability was determined after $72 \mathrm{~h}$ of exposure. To assess cell viability, we used three end-point methods: the ATP content was measured using the CellTiter-Glo Luminescent Viability Assay (Promega, G7570), MTT assay, and determination of cell counts (384-well plates) of treated and control cells at $72 \mathrm{~h}$ by optical microscopy. The output data represent results of three independent experiments. For a detailed method description, see the Supporting Information.

\section{ASSOCIATED CONTENT}

Supporting Information

Additional details on methods and results concerning the phylogenetic analysis, genomic and bioinformatic analysis, HPLC-MS/MS, NMR and cytotoxicity tests; Supporting Figures 1-6; and Supporting Tables 1-7 (PDF)

Accession Codes

PGEM00000000.1 and MG518226.

AUTHOR INFORMATION

ORCID

Andreja Kust: 0000-0003-4016-6454

Jouni Jokela: 0000-0001-5096-3575

David P. Fewer: 0000-0003-3978-4845 
Kaarina Sivonen: 0000-0002-2904-0458

Pavel Hrouzek: 0000-0002-2061-0266

Notes

The authors declare no competing financial interest.

\section{ACKNOWLEDGMENTS}

This work was supported by the Czech Science Foundation grant number 14-18067S; the grant of the Faculty of Science, University of South Bohemia GAJU 158/2016/P; Ministry of Education, Youth and Sports of the Czech Republic - National Programme of Sustainability I grant number LO1416 and ALGAMIC project grant number CZ.1.05/2.1.00/19.0392. Access to instruments and other facilities was supported by the Czech research infrastructure for systems biology C4SYS (grant number LM2015055). This work was also supported by the Academy of Finland grant 1273798 to K.S. We would like to thank E. Kozlik ova'-Zapomel' ová and K. Čapková for isolating and maintaining the strain, T. Galica for help with formatting of Figure 2,,, and M. Mehrshad for help with sequence annotation.

\section{REFERENCES}

(1) Frank, J.-H., and Kanamitsu, K. (1987) Paederus, sensu lato (Coleoptera: Staphylinidae): natural history and medical importance. J. Med. Entomol. 24, 155-191.

(2) Ueta, A. (1949) J. Kurume. Med. College, Kyushu, 2489.

(3) Pavan, M., and Bo, G. (1953) Pederin, toxic principles obtained in the crystalline state from the beetle Paederus f uscipes Curt. Physiol. Comp. Oecol. 3, 307-312.

(4) Piel, J. (2002) A polyketide synthase-peptide synthetase gene cluster from an uncultured bacterial symbiont of Paederus beetles. Proc. Natl. Acad. Sci. U. S. A. 99, 14002-14007.

(5) Helfrich, E.-J.-N., and Piel, J. (2016) Biosynthesis of polyketides by trans-AT polyketide synthases. Nat. Prod. Rep. 33, 231-316.

(6) Kampa, A., Gagunashvili, A.-N., Gulder, T.-A.-M., Morinaka, B. I., Daolio, C., Godejohann, M., Miao, V.-P.-W., Piel, J., and Andresson, O.-S. (2013) Metagenomic natural product discovery in lichen provides evidence for a family of biosynthetic pathways in diverse symbioses. Proc. Natl. Acad. Sci. U. S. A. 110, E3129-E3137.

(7) Wilson, M.-C., Mori, T., Ruckert, C., Uria, A.-R., Helf, M.-J., Takada, K., Gernert, C., Steffens, U.A.-E., Heycke, N., Schmitt, S., Rinke, C., Helfrich, E.-J.-N., Brachmann, A.- O., Gurgui, C., Wakimoto, T., Kracht, M., Crusemann, M., Hentschel, U., Abe, I., Matsunaga, S., Kalinowski, J., Takeyama, H., and Piel, J. (2014) An environmental bacterial taxon with a large and distinct metabolic repertoire. Nature 506, 58-62.

(8) Freeman, M.-F., Vagstad, A.-L., and Piel, J. (2016) Polytheonamide biosynthesis showcasing the metabolic potential of sponge-associated uncultivated 'Entotheonella' bacteria. Curr. Opin. Chem. Biol. 31, 8-14.

(9) Piel, J., Hui, D.-Q., Wen, G.-P., Butzke, D., Platzer, M., Fusetani, N., and Matsunaga, S. (2004) Antitumor polyketide biosynthesis by an uncultivated bacterial symbiont of the marine sponge Theonella swinhoei. Proc. Natl. Acad. Sci. U. S. A. 101, 16222-16227.

(10) Fisch, K.-M., Gurgui, C., Heycke, N., van der Sar, S.-A., Anderson, S.-A., Webb, V.-L., Taudien, S., Platzer, M., Rubio, B.-K.,

Robinson, S.-J., Crews, P., and Piel, J. (2009) Polyketide assembly lines of uncultivated sponge symbionts from structure-based gene targeting. Nat. Chem. Biol. 5, 494-501. 
(11) Nakabachi, A., Ueoka, R., Oshima, K., Teta, R., Mangoni, A., Gurgui, M., Oldham, N.-J., van Echten-Deckert, G., Okamura, K., Yamamoto, K., Inoue, H., Ohkuma, M., Hongoh, Y., Miyagishima, S., Hattori, M., Piel, J., and Fukatsu, T. (2013) Defensive bacteriome symbiont with a drastically reduced genome. Curr. Biol. 23, 1478-1484.

(12) Liaimer, A., Jensen, J.-B., and Dittmann, E. (2016) A genetic and chemical perspective on symbiotic recruitment of cyanobacteria of the genus Nostoc into the host plant Blasia pusilla $\mathrm{L}$. Front. Microbiol. 7,1693.

(13) Schleissner, C., Canedo, L.-M., Rodriguez, P., Crespo, C., Zuniga, P., Penalver, A., de la Calle, F., and Cuevas, C. (2017)

Bacterial production of a pederin analogue by a free-living marine Alphaproteobacterium. J. Nat. Prod. 80, 2170-2173.

(14) Kaštovský, J., Hauer, T., Mareš, J., Krautová, M., Bešta, T., Komárek, J., Desortová, B., Heteša, J., Hindáková, A., Houk, V., Janeček, E., Kopp, R., Marvan, P., Pumann, P., Skácelová, O., and Zapomělová, E. (2010) A review of the alien and expansive species of freshwater cyanobacteria and algae in the Czech Republic. Biol. Invasions 12, 3599-3625.

(15) Ueoka, R., Uria, A.-R., Reiter, S., Mori, T., Karbaum, P., Peters, E.-E., Helfrich, E.-J.-N., Morinaka, B.-I., Gugger, M., Takeyama, H., Matsunaga, S., and Piel, J. (2015) Metabolic and evolutionary origin of actin-binding polyketides from diverse organisms. Nat. Chem. Biol. 11, 705-712.

(16) Caffrey, P. (2003) Conserved amino acid residues correlating with ketoreductase stereospecificity in modular polyketide synthases. ChemBioChem 4, 654-657.

(17) Reid, R., Piagentini, M., Rodriguez, E., Ashley, G., Viswanathan, N., Carney, J., Santi, D. - V., Hutchinson, C. - R., and McDaniel, R. (2003) A model of structure and catalysis for ketoreductase domains in modular polyketide synthases. Biochemistry 42, 72-79.

(18) Mosey, R.-A., and Floreancig, P.-E. (2012) Isolation, biological activity, synthesis, and medicinal chemistry of the pederin/mycalamide family of natural products. Nat. Prod. Rep. 29, 980-995.

(19) Wan, S.-Y., Wu, F.-H., Rech, J.-C., Green, M.-E., Balachandran, R., Horne, W.-S., Day, B.-W., and Floreancig, P.-E. (2011) Total synthesis and biological evaluation of pederin, psymberin, and highly potent analogs. J. Am. Chem. Soc. 133, 16668-16679.

(20) Selwood, A.-I., Holland, P.-T., Wood, S.-A., Smith, K.-F., and McNabb, P.-S. (2007) Production of anatoxin-a and a novel

biosynthetic precursor by the cyanobacterium Aphanizomenon issatschenkoi. Environ. Sci.

Technol. 41, 506-510.

(21) Guillard, R. L., and Lorenzen, C. J. (1972) Yellow-green algae with chlorophyllide c. J. Phycol. 8, 10-14.

(22) Komárek, J. (2013) Cyanoprokaryota. 3. Heterocytous Genera, in Süswasserflora von Mitteleuropa/Freshwater Flora of Central Europe (Büdel, B., Gärtner, G., Krienitz, L., and Schagerl, M., Eds), pp 1130, Springer Spektrum.

(23) Mareš, J., Hájek, J., Urajová, P., Kopecký, J., and Hrouzek, P. (2014) A hybrid non-ribosomal peptide/polyketide synthetase containing fatty-acyl ligase (FAAL) synthesizes the beta-amino fatty acid lipopeptides puwainaphycins in the cyanobacterium Cylindrospermum alatosporum. PLoS One 9, e111904.

(24) Delcher, A.-L., Bratke, K.-A., Powers, E.-C., and Salzberg, S.-L. (2007) Identifying bacterial genes and endosymbiont DNA with Glimmer. Bioinformatics 23, 673-679.

(25) Blin, K., Wolf, T., Chevrette, M. G., Lu, X.-W., Schwalen, C. J., Kautsar, S. A., Suarez Duran, H. G., de los Santos, E. L. C., Kim, H. U., Nave, M., Dickschat, J. S., Mitchell, D. A., Shelest, E., Breitling, 
R., Takano, E., Lee, S. Y., Weber, T., and Medema, M. H. (2017) antiSMASH 4.0-improvements in chemistry prediction and gene cluster boundary identification. Nucleic Acids Res. 45, W36-W41.

Figure 1. Phylogenetic position of Cuspidothrix issatschenkoi CHARLIE-1 among the producers of pederin family compounds. The unrooted tree was inferred from 16S rRNA gene data using Bayesian Inference (BI). BI posterior probabilities are indicated near nodes. The major bacterial lineages containing producers of pederin analogues are color-shaded. The strains producing pederin family compounds are printed in red; representative structures of the products are shown for each group.

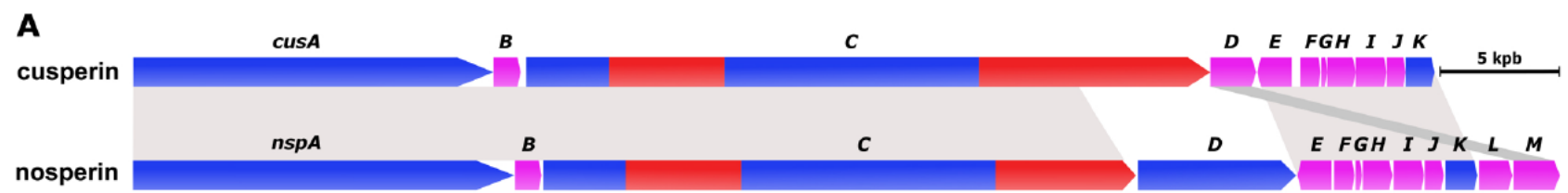

B

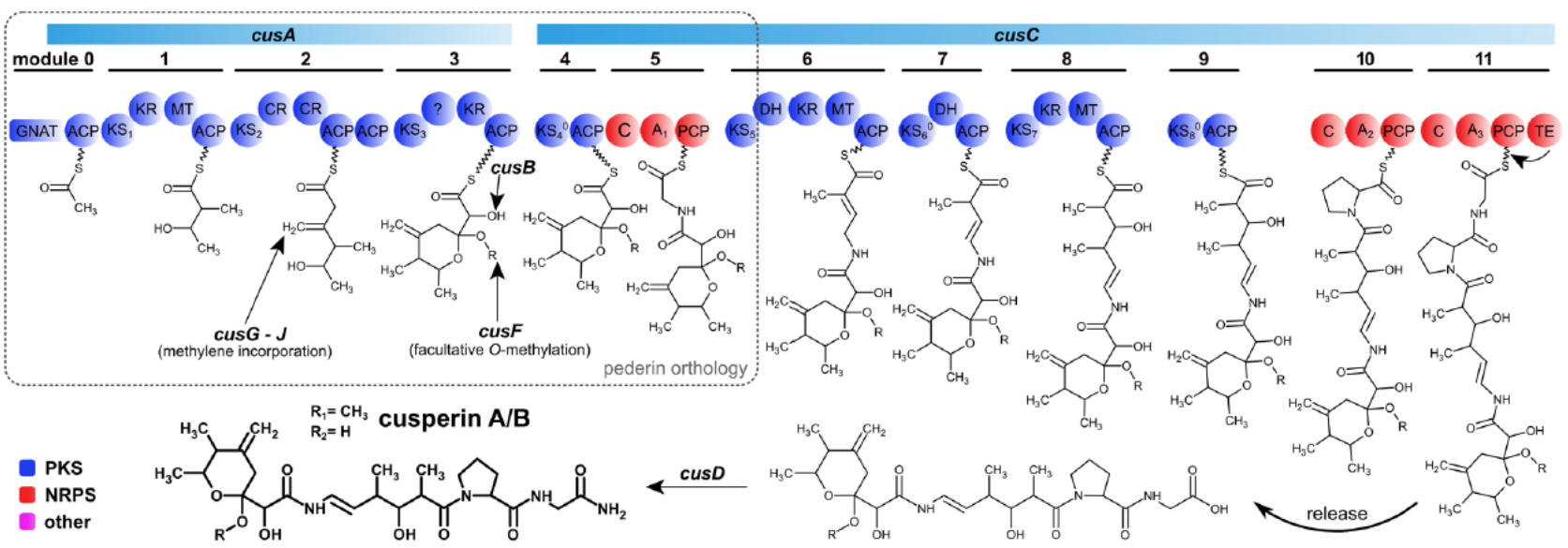

Figure 2. Predicted biosynthetic pathway of cusperin. (a) Gene arrangement of the proposed cusperin biosynthetic gene cluster and comparison to nosperin biosynthetic gene cluster. Homologous regions are indicated by gray shading. (b) Proposed biosynthesis of cusperin A and B is collinear with the arrangement of modules in CusA and CusC. Part of the pathway orthologous to pederin, onnamides, theopederins, and diaphorin is indicated by a dashed box. The structure of nosperin is shown for comparison; differences from cusperin $A$ are highlighted in red color. $A$, adenylation domain; $A C P$, acyl carrier protein; $C$, condensation domain; $C R$, crotonase (enoyl-CoA hydratase); DH, dehydratase; GNAT, GCN5-related N-acetyltransferase; MT, methyltransferase; NRPS, nonribosomal peptide synthetase; KR, ketoreductase; KS, ketosynthase; PCP, peptidyl carrier protein; PKS, polyketide synthase; TE, thioesterase. 

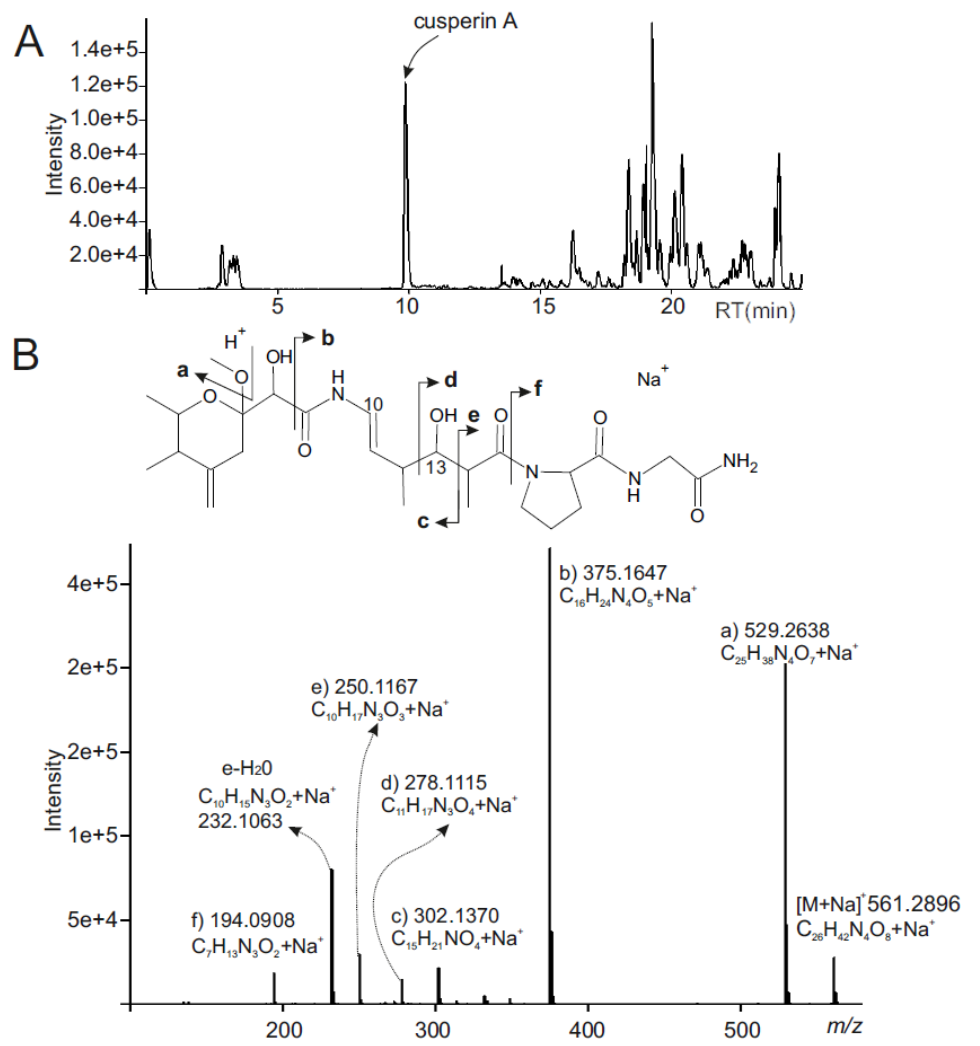

Figure 3. Structural analysis of cusperin A. (a) HPLC-HRMS/MS base peak chromatogram of Cuspidothrix crude extract. (b) Fragmentation pattern and HRMS/MS spectrum of cusperin A.

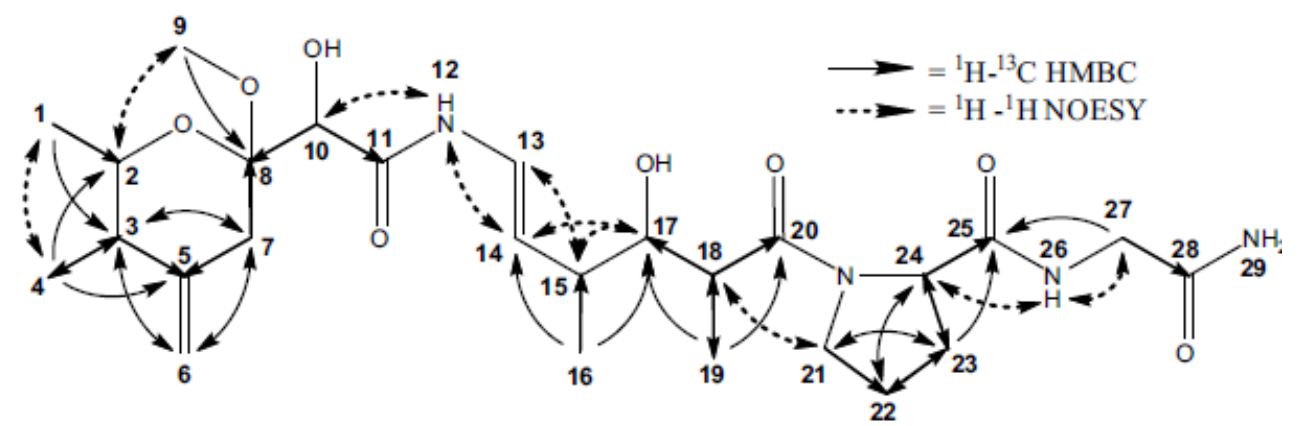

Figure 4. NMR analysis and stereochemical assignment of cusperin A. (a) $13 \mathrm{C} \mathrm{HMBC} \mathrm{(solid} \mathrm{arrows)}$ and $1 \mathrm{H}-1 \mathrm{H}$ NOESY (dashed arrows) correlations of cusperin. (b) Stereochemical arrangement of cusperin chiral centers based on NMR and bioinformatic analysis. Blue, domain organization identical to nosperin, supporting a similar arrangement of chiral centers; red, NMR coupling constants and shifts; yellow, ketoreductases (KRs) predicted specificity based on a specific sequence motif (the presence of a conserved Asp residue); green, nonribosomal peptide synthase (NRPS) domain prediction (absence of an epimerase domain). 